\title{
A new allele for aluminium tolerance gene in barley (Hordeum vulgare L.)
}

\author{
Yanling Ma', Chengdao Li ${ }^{2}$, Peter R. Ryan³, Sergey Shabala', Jianfeng You ${ }^{3}$, Jie Liư ${ }^{1,3}$, Chunji Liu ${ }^{4}$ \\ and Meixue Zhou $^{1 *}$
}

\begin{abstract}
Background: Aluminium (Al) toxicity is the main factor limiting the crop production in acid soils and barley (Hordeum vulgare $\mathrm{L}$.) is one of the most Al-sensitive of the small-grained cereals. The major gene for Al tolerance in barley is HVAACT1 (HVMATE) on chromosome 4H which encodes a multidrug and toxic compound extrusion (MATE) protein. The HVAACT1 protein facilitates the Al-activated release of citrate from root apices which protects the growing cells and enables root elongation to continue. A $1 \mathrm{~kb}$ transposable element-like insert in the $5^{\prime}$ untranslated region (UTR) of HVAACT1 is associated with increased gene expression and tolerance and a PCR-based marker is available to score for this insertion.

Results: We screened a wide range of barley genotypes for Al tolerance and identified a moderately tolerant Chinese genotype named CXHKSL which did not show the typical allele in the 5' UTR of HVAACT1 associated with tolerance. We investigated the mechanism of Al tolerance in CXHKSL and concluded it also relies on the Alactivated release of citrate from roots. Quantitative trait loci (QTL) analysis of double haploid lines generated with CXHKSL and the Al-sensitive variety Gairdner mapped the tolerance locus to the same region as HVAACT1 on chromosome $4 \mathrm{H}$.
\end{abstract}

Conclusions: Our results show that the Chinese barley genotype CXHKSL possesses a novel allele of the major $\mathrm{Al}$ tolerance gene HvAACT1.

Keywords: Aluminium tolerance, Barley, HvAACT1

\section{Background}

Aluminium ( $\mathrm{Al})$ is the most abundant metal in the earth crust. $\mathrm{Al}$ can be toxic to plants when the concentration of soluble $\mathrm{Al}$ increases in acidic soils $(<\mathrm{pH} 5.0)$ due to the formation of the phytotoxic $\mathrm{Al}^{3+}$ species. An early symptom of $\mathrm{Al}$ toxicity is the inhibition of root elongation which limits water and nutrient uptake [1-3]. The inhibition of root growth in wheat (Triticum aestivum L.) occurs within minutes or hours in simple hydroponic solutions [4] due to decreases in root cell division and elongation [5]. Longer treatments result in thickened roots, damaged root cap, and lesions in the epidermal and cortical tissues near the root apices [6-8]. Additional symptoms of stress in wheat and maize roots

\footnotetext{
* Correspondence: mzhou@utas.edu.au

${ }^{1}$ Tasmanian Institute of Agriculture and School of Land and Food, University of Tasmania, P.O. Box 46, Kings Meadows, TAS 7249, Australia

Full list of author information is available at the end of the article
}

include the appearance of large swollen cortical cells near the root tip $[9,10]$.

An important mechanism of resistance in many species relies on the exclusion of $\mathrm{Al}$ from root tissues by the release of organic anions from the root apices. The organic anions such as malate and citrate chelate the harmful $\mathrm{Al}$ cations in the apoplast and prevent them damaging the root tissues [11-13]. Barley (Hordeum vulgare L.) is one of the most Al-sensitive cereal species yet it still shows genotypic variation [14]. A mechanism for $\mathrm{Al}$ tolerance described in barley relies on the Alactivated release of citrate from root apices. This is controlled by a single major locus called Alp on chromosome 4HL [15-17]. The gene underlying the Alp locus is HvAACT1 which encodes a member of the multidrug and toxic compound extrusion (MATE) family $[8,14$, 17, 18]. This gene has been linked with tolerance in many genotypes of barley including Murasakimochi, Dayton, Honen, WB229, Svanhals, Br2 and Brindabella 
[16, 19-22]. Tolerant genotypes of barley show a constitutively higher expression of $H v A A C T 1$ in root apices than sensitive genotypes. Furthermore, constitutively over-expression of $H v A A C T 1$ in transgenic barley and wheat plants significantly increases the Al-activated citrate efflux and their tolerance to $\mathrm{Al}$ in hydroponic solution and in acid soil [8].

The higher expression of $H v A A C T 1$ in tolerant barley was recently linked to the presence of a 1023-bp transposable-element like insertion in the 5' untranslated region (UTR) of $H v A A C T 1$ [23]. This insertion alters the usual distribution and level of $H v A A C T 1$ expression such that it becomes constitutively high in the root apices $[11,23]$. This mutation is only found in cultivated Al-tolerant barley genotypes from East Asia where acid soils are prevalent and likely represents an important mutation that has helped the expansion of barley from the Near East where the soils are rarely acidic [23].

A PCR-based marker can be used to detect the presence or absence of the insert in the 5' UTR of HvAACT1 and this is a convenient method for screening barley for Al tolerance $[19,23]$. The PCR product from tolerant barley genotypes is approximately $1 \mathrm{~kb}$ larger than the product from sensitive barley genotypes [23]. Another gene-specific marker called $H v M A T E-21$ was designed to target polymorphism at the 3' UTR of HvAACT1 and this marker has been used successfully to score more than 50 varieties differing in Al tolerance [18]. All tolerant varieties tested possessed the 21-bp deletion compared with the sensitive varieties. Using association analysis the HvMATE-21 marker could explain $66.9 \%$ of phenotypic variation for Al tolerance [18]. Meanwhile, several simple sequence repeats (SSR) markers such as Bmac310, Bmag353 and HVM03 are closely linked with tolerance and commonly used for genetic analysis [16, 20, 24].

In this study, we identified a Chinese barley variety, CXHKSL, which was moderately tolerant to acid soil (Additional file 1: Table S1) but which gave a nonstandard result for the 5' UTR HvAACT1 marker. This indicated that $\mathrm{Al}$ tolerance in CXHKSL might be controlled or regulated in a different way. We investigated the Al tolerance mechanism in CXHKSL and mapped the trait using a double haploid (DH) population derived from CXHKSL and the Al-sensitive variety Gairdner.

\section{Methods}

\section{Genetic materials}

CXHKSL is a six-rowed Chinese variety that is tolerant to acid soils. The Al-sensitive variety, Gairdner, is an Australian malting barley. The Al tolerant variety, Dayton, was used as a control when investigating tolerance mechanisms of CXHKSL. One DH population consisting of 210 lines derived from a cross between CXHKSL and Gairdner was used for QTL mapping study.

\section{Al tolerance and root growth}

The relative $\mathrm{Al}$ tolerance of the different varieties and selected double haploid lines (DHLs) were evaluated with hydroponic culture methods. Sterilized seeds were germinated in the dark for 2 days at $4{ }^{\circ} \mathrm{C}$ and then 2 days at $28{ }^{\circ} \mathrm{C}$. Root length of the seedlings was measured and they were placed in an aerated nutrient solution containing $500 \mu \mathrm{M} \mathrm{KNO}_{3}, 500 \mu \mathrm{M}$ $\mathrm{CaCl}_{2}, 500 \mu \mathrm{M} \mathrm{NH}_{4} \mathrm{NO}_{3}, 150 \mu \mathrm{M} \mathrm{MgSO}_{4}, 10 \mu \mathrm{M}$ $\mathrm{KH}_{2} \mathrm{PO} 4,2 \mu \mathrm{M}$ Fe:EDTA, $11 \mu \mathrm{M} \quad \mathrm{H}_{3} \mathrm{BO}_{3}, 2 \mu \mathrm{M}$ $\mathrm{MnCl}_{2}, 0.35 \mu \mathrm{M} \mathrm{ZnCl}$ and $0.2 \mu \mathrm{M} \mathrm{CuCl}$. For barley, $\mathrm{Al}$ tolerance was estimated by measuring net root length after 4 days in 0,1 , and $4 \mu \mathrm{M} \mathrm{AlCl}{ }_{3}(\mathrm{pH}=$ $4.3)$, respectively. Relative root length (RRL) was estimated as: (net root growth in $\mathrm{Al}$ treatment/net root growth in control solution) $\times 100 \%$ [8]. Meanwhile, 4-day old control and $4 \mu \mathrm{M} \mathrm{AlCl}_{3}$ treated seedlings roots were stained with haematoxylin for $15 \mathrm{~min}$ and rinsed for $10 \mathrm{~min}$ to compare the density of $\mathrm{Al} \mathrm{accu}$ mulation at root apices. Haematoxylin could form a purple-red complex with $\mathrm{Al}$ and provides an indirect of non-complexed $\mathrm{Al}$ in root apices, with the intensity of staining correlated with sensitivity of $\mathrm{Al}$ toxicity [25].

Al tolerance was also scored using acid soil collected from the Northern Tasmania $(\mathrm{pH}=4.3)$. Three seeds of each DHL and parent varieties were sown in the acid soil in each replicate. Two independent experiments including six replicates were conducted in April and June 2013, respectively. Four replications were applied in each experiment. Both root length and root morphology were used to assess Al tolerance. Root length ( $\mathrm{mm})$ of each seedling was measured seven days after sowing. Meanwhile, root tips were screened for the absence or presence of thickening caused by $\mathrm{Al}$ toxicity.

\section{Assaying citrate efflux and malate efflux from root apices} Seedlings were grown for 4 days in the nutrient solution described above (without added $\mathrm{AlCl}_{3}$ ). To study if the expression of $H v A A C T 1$ need longer $\mathrm{Al}$ treatment duration, half of the plants of each genotype were subjected to $0.2 \mathrm{mM} \mathrm{CaCl}{ }_{2}$ solution containing $10 \mu \mathrm{M} \mathrm{AlCl}{ }_{3}(\mathrm{pH}=4.3)$ for overnight pre-treatment. Ten root apices $(3-5 \mathrm{~mm})$ with 4 replicates were excised from the same line and washed in $1 \mathrm{ml} 0.2 \mathrm{mM}$ $\mathrm{CaCl}_{2}$ solution $(\mathrm{pH}=4.3)$ for on a platform shaker (60 rpm). After $30 \mathrm{~min}$ washing, $1 \mathrm{ml} 0.2 \mathrm{mM} \mathrm{CaCl}_{2}$ solution $(\mathrm{pH}=4.3)$ with $30 \mu \mathrm{M} \mathrm{AlCl}_{3}$ was added and shaken for $2 \mathrm{~h}$ at $60 \mathrm{rpm}$. The solutions were centrifuged to dryness on a rotary vacuum drier for citrate efflux detection. The enzyme assay used to determine 
citrate concentration is described by Wang et al. [16]. The initial citrate content in each sample was calculated from a standard curve. Malate concentration was measured with an enzyme assay as described previously [26].

\section{Molecular marker analysis}

Three primer pairs were used to investigate allelic variation in the 5'UTR of HvAACT1. These were to detect the presence or absence of a $\sim 1 \mathrm{~kb}$ transposon-like insertion previously described in Al-tolerant genotypes of barley. The first pair of primers was from Fujii et al. [23] with forward sequence 5'-GGTCCAACACTCTACCCT CCTT and reverse 5'-GGTGCGAG -TTGCCCCTAGCTATTA. The second pair of primers described by Bian et al. [18] was forward 5'-CTTCATTTCAACCAAGCACTCC and reverse 5'-GCTTTTGGTCGAACAAAGTATCG. The third pair of primers was designed to amplify a slightly larger fragment that included the above two pairs of primers comprised, forward 5'TGTCGATATGGTGCTCTT -CG and reverse 5'AGCTCCATGACAATTCTGGG. PCR reactions were performed at $20 \mu \mathrm{l}$-volume including $10 \mu \mathrm{l}$ HotstarTaq $^{\text {TM }}$ master mix (Qiagen), $2 \mu \mathrm{l}$ primer mix (1:1 mix of forward and reverse primers at $10 \mathrm{nM}), 3 \mu \mathrm{l}$ DNA template, and $5 \mu \mathrm{H}_{2} \mathrm{O}$. Cycling conditions were as follows: 1 cycle of $1 \mathrm{~min}$ at $95{ }^{\circ} \mathrm{C}, 35$ cycles of $1 \mathrm{~min}$ at $95{ }^{\circ} \mathrm{C}$, $30 \mathrm{~s}$ at $60^{\circ} \mathrm{C}, 40 \mathrm{~s}$ at $72{ }^{\circ} \mathrm{C}$, and finally with an extension step of $1 \mathrm{~min}$ at $72{ }^{\circ} \mathrm{C}$. All PCR reactions were run at C1000 ${ }^{\mathrm{TM}}$ Thermal cycler (BIO-RAD). PCR products were separated at $1 \%$ agarose and visualized by staining with $1 \%$ Red safe under Gel Doc ${ }^{\mathrm{TM}} \mathrm{XR}^{+}$imagining system (BIO-RAD).

Another HvAACT1-specific marker, HvMATE-21, was used to genotype the population as well as three closely HvAACT1-linked SSR markers: Bmac310, Bmag353 and HVM03 [14, 16, 19]. HvMATE-21 was a PCR marker that detected the presence or absence of a 21-bp fragment in the 3' UTR of HvAACT1. PCR reactions were carried out in a total volume of $15 \mu \mathrm{l}$ containing 25 30 ng genomic DNA, 0.5 M of forward and reverse primers, $7.5 \mu$ GoTaq $^{\circ}$ Hot Start Colorless Master Mix, 2X (Promega). The amplification of SSRs were performed by: 1 cycle of $3 \mathrm{~min}$ at $94{ }^{\circ} \mathrm{C}, 35$ cycles of $1 \mathrm{~min}$ at $94{ }^{\circ} \mathrm{C}, 1 \mathrm{~min}$ at the annealing temperature $55{ }^{\circ} \mathrm{C}$ and $1 \mathrm{~min}$ at $72{ }^{\circ} \mathrm{C}$, with a final extension step of $5 \mathrm{~min}$ at $72{ }^{\circ} \mathrm{C}$. The PCR profiles for HvMATE-21 were almost the same as that for SSR markers except the annealing temperature was $60{ }^{\circ} \mathrm{C}$. All PCR reactions were run on Mastercycler Gradient 5331 (Eppendorf AG, Germany). The PCR products were separated on $5 \%$ denatured polyacrylamide gels and visualized by a rapid silver staining method [27].
Isolation and sequence analysis of coding region of HvACCT1 gene in CXHKSL and Dayton

The published complete coding DNA sequence (CDS) of HvAACT1 gene (Genebank: AB302223.1) was retrieved from the National Center for Biotechnology Information (NCBI, http://www.ncbi.nlm.nih.gov/gene) and aligned with barley reference genome data using IPK blast server (http://webblast.ipk-gatersleben.de/barley/viroblast.php). Based on the best hit sequence, a total of 4 pairs of primers (Additional file 2: Table S2) were used to amplify the whole $H v A C C T 1$ open reading frames (ORFs). The amplified PCR products was purified and cloned with $\mathrm{PGEM}^{\ominus}$-T Vector System (Promega). The final CDS were constructed using sequencing results from 12 independent clones (3 clones for each pair of primers). Sequence analysis was completed with software DNAMAN (version 7.0; Lynnon Biosoft, USA). The sequence data of CDS have been deposited to NCBI Genbank Database with accession number of KU725980 for variety CXHKSL and KU725981 for Dayton.

\section{HvAACT1 expression}

RNA was isolated from root apices (also from plants used for citrate efflux measurement) by $\mathrm{RNeasy}^{\mathrm{TM}}$ plant kit (Qiagen) and purified by inclusion of RNase-free DNase (Qiagen). One microgram total RNA was used to synthesize cDNA by reverse transcriptase system (Invitrogen). $1.0 \mu \mathrm{l}$ oligo primer was added into $11.5 \mu \mathrm{l}$ reaction mixture including $1 \mu \mathrm{g}$ RNA. The mixture was incubated at $70{ }^{\circ} \mathrm{C}$ for $10 \mathrm{~min}$, and transferred to ice immediately. Each aliquot included $4 \mu \mathrm{l}$ buffer, $2 \mu \mathrm{l} 0.1 \mathrm{M}$ DTT, $1 \mu \mathrm{l}$ dNTP mix, and $0.5 \mu \mathrm{l}$ superscript III Reverse Transcriptase was added into the mixture, and incubated at $42{ }^{\circ} \mathrm{C}$ for $1 \mathrm{~h}$. RNA degradation step was performed by addition of $0.25 \mu \mathrm{l}$ RNase $\mathrm{H}$ (Thermo Scientific $^{\mathrm{TM}}$ ) and incubated at $37^{\circ} \mathrm{C}$ f or $30 \mathrm{~min}$.

Quantification real time polymerase chain reaction(RT-PCR) was run in a C1000TM Thermal cycler (BIO-RAD) with $10 \mu \mathrm{l}$ reaction mixture containing $4.0 \mu \mathrm{l}$ of cDNA diluted to 1:40, $5 \mu \mathrm{l}$ of SYBR Green Jumpstart Taq Readymix (Sigma) and $1 \mu \mathrm{l}$ primer mix (1:1 mix of forward and reverse primers at $10 \mathrm{nM})$. Three pairs of primers used to measure expression of $H v A A C T 1$ (HvAACT1-forward 5'-AGCAGCCAAGACCTTGAGAA and reverse 5'AGCAG GAATCCACAACCAAG; NewHvAACT1-1-forward ACGGGGCTCTACCTCTTT -GT and reverse 5'-GGCAATAGAAACACCAACAGC; NewHvAACT1-2-forward CTGTGTCACTC TGGCATCGT, and reverse 5-AAGCTGCAGAACACGAGAGGT). The constitutively expressed barley glyceraldehyde-3-phosphate dehydrogenase (HvGAPDH) gene and barley homologous to eukaryotic translation elongation factor $1 \mathrm{~A}$ (HveEF-1A) gene was used as reference genes. The sequences of primers are as follows: $H v G A P D H$-forward: 
5'-GTGAGG CTGGTGCTGATTACG and reverse 5'-TGGTGCAGCTAGCATTTGAGAC, HveEF-1A-forward 5'-TTTCACTCTTGGTGTGAAGCAGAT and reverse 5'-GACTTCCTTCACGAT-TTCATCGTAA. Cycling conditions were $3 \mathrm{~min}$ at $95^{\circ} \mathrm{C}$, followed by 40 cycles at $95{ }^{\circ} \mathrm{C}$ for $10 \mathrm{~s}, 60^{\circ} \mathrm{C}$ for $20 \mathrm{~s}, 68^{\circ} \mathrm{C}$ for $10 \mathrm{~s}$. At the end, a melting curve of the amplified fragments was produced by increasing the temperature every $0.5{ }^{\circ} \mathrm{C}$ from $60{ }^{\circ} \mathrm{C}$ to $95{ }^{\circ} \mathrm{C}$.

\section{Data analysis and QTL mapping}

All phenotypic data was analysed by SPSS software package (Version 20.0, IBM), including all basic statistics calculation and Chi-Square Goodness of Fit Test. For genetic linkage map analysis, the genetic distances between molecular markers were calculated using software JoinMap 4.0 [28]. The mean values of root lengths of DHLs were used to detect QTL affecting root length under Al toxicity with software MapQTL6 [29]. Interval mapping (IM) method was first used to identify the major QTL. By selecting significantly linked markers as cofactors, multiple QTL mapping (MQM) mapping method based on the multiple-QTL model was used. A set of 1000 permutations was performed to identify the LOD threshold corresponding to a genome-wide false discovery rate of $5 \%$ $(P<0.05)[29]$.

\section{Results}

A PCR-based marker is available to score for the presence or absence of the $\sim 1 \mathrm{~kb}$ insert in the $5{ }^{\prime} \mathrm{UTR}$ of the HvAACT1 associated with higher expression in the root apices of Al-tolerant barley [23]. The marker generates a larger product in Al-tolerant genotypes than in sensitive genotypes. A Chinese variety named CXHKSL was identified which was tolerant to acid soil but did not show the typical marker result associated with tolerance. In fact the standard PCR reaction failed to produce any PCR band in CXHKSL while the results obtained from control varieties including the highly tolerant variety, Dayton, and sensitive variety, Gairdner, were as expected (Fig. 1a). The failure to generate a band was not related to the quality or quantity of DNA extracted from CXHKSL since other PCR reactions were successful including the HvMATE-21 marker which targets the 3' UTR of HvAACT1 (data not shown). Polymorphisms in CXHKSL may have reduced annealing temperature of one or both primers and so two additional primer pairs were designed to target this polymorphic region in the 5', UTR of HvAACT1 (Fig. 1b, c). One set had primers farther upstream and downstream from the first set and therefore would amplify a slightly larger product (Fig. 1c). The second set of primers (Fig. 1b) was previously described by Bian et al. [18]. Using these additional primers, PCR products of the expected size were reliably generated from Dayton and Gairdner. By contrast CXHKSL generated no products at all (Fig. 1b, c). By contrast the HvMATE-21 marker for CXHKSL, Dayton and Gairdner were as described by Bian et al. [18]: the tolerant genotype possessed a 21-bp deletion but sensitive genotypes did not (data not shown). The coding region of HVAACT1 in both CXHKSL and Dayton consisted of $1668 \mathrm{bp}$ which is the same as previously published CDS [15]. CXHKSL was similar to Dayton with only one nucleotide being different for $H v A A C T 1$ coding region (Additional file 3: Figure S1) and the

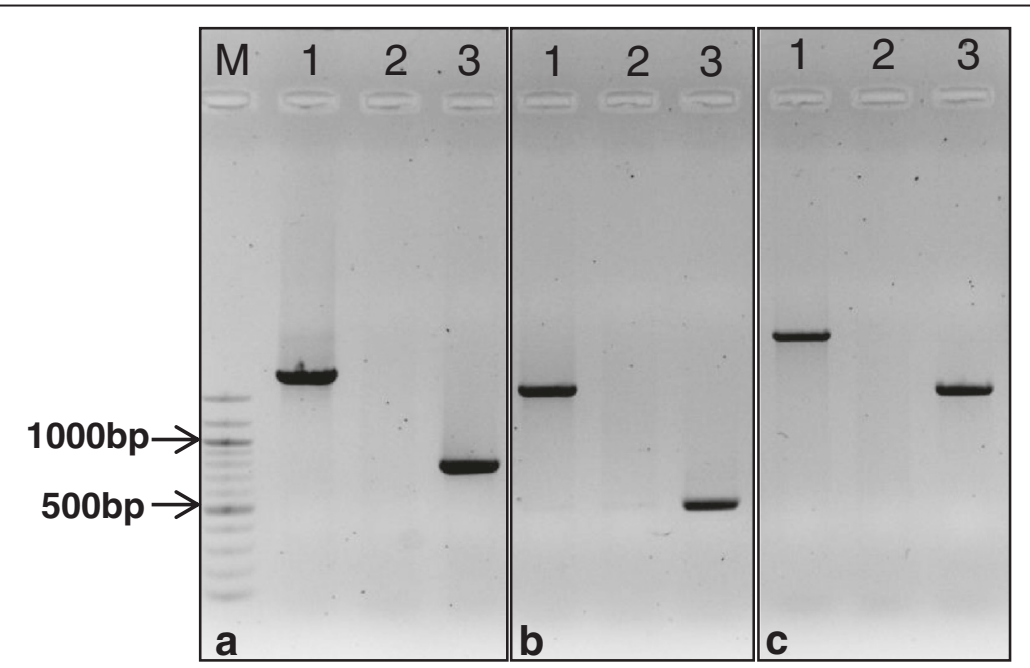

Fig. 1 Testing presence of the 1-kb transposon-like insertion in the 5'UTR of HVAACT1 associated with Al tolerance. Primers sets used in the PCR reactions are listed: (a) from Fujii et al. [23] (b) from Bian et al. [18] and (c) a new set of primers farther upstream and downstream from those used in (a) (see Methods). Varieties are Dayton (1), CXHKSL (2) and Gairdner (3) 
difference didn't cause any changes in amino acids. Two and three SNPs were detected between the published CDS and CXHKSL and between the CDS and Dayton, respectively.

The Al tolerance of CXHKSL was further investigated in hydroponic experiments and compared with Dayton and Gairdner. Relative root length (RRL) of CXHKSL was $\sim 75 \%$ after four days in $4 \mu \mathrm{M} \mathrm{AlCl}_{3}$ which was significantly greater than Gairdner ( $30 \%$ RRL) but less than Dayton ( $110 \%$ RRL) (Fig. 2). This ranking was similar to the Al-related tissue damage on roots in the three varieties (Fig. 3). Root apices of Gairdner became significantly thicker than the others after four days in $4 \mu \mathrm{M} \mathrm{AlCl}$ which is a typical symptom of $\mathrm{Al}$ toxicity. Haematoxylin staining was also more intense in the root apices of Gairdner than in Dayton or CXHKSL, indicating greater $\mathrm{Al}$ accumulation in the roots of Gairdner. The Al-dependent efflux of citrate was then measured from these barley lines. Citrate efflux from CXHKSL was less than Dayton $\left(\sim 40 \mathrm{pmol} \cdot \mathrm{apex}^{-1} \cdot \mathrm{h}^{-1}\right)$ but greater than Gairdner which correlated well with their relative tolerance to $\mathrm{Al}$ (Fig. 4a). Pre-treatment with $\mathrm{Al}$ prior to these measurements did not increase citrate efflux further compared with roots without pre-treatment (Fig. 4a).
These results indicate that the mechanism of $\mathrm{Al}$ tolerance in CXHKSL is associated with $\mathrm{Al}$-activated citrate efflux from roots which is consistent with previous reports for barley $[14,16]$. We also investigated whether $\mathrm{Al}$-activated malate release from the roots of CXHKSL was apparent but we found no indication of efflux from this in any barley lines tested (Fig. 4b). An Al-tolerant wheat line included as a positive control in this experiment showed malate efflux of $0.9 \mathrm{nmol} \mathrm{apex}{ }^{-1} \mathrm{~h}^{-1}$ which is similar to published values [26].

The chromosomal location of the tolerance locus in CXHKSL was investigated using a doubled haploid population generated by crossing CXHKSL and Gairdner. A total of 210 DHLs were grown in the acid soil and the roots were scored based on both root length and root tip damage (thickness). Root length of the CXHKSL parent was $75 \pm 8 \mathrm{~mm}$ and showed no damage of root tips (Fig. 5; Fig. 6a). Root length of the Gairdner was $40 \pm 5 \mathrm{~mm}$ and the root apices showed swelling, thickening and clear signs of damage (Fig. 5; Fig. 6b). A total of 65 DHLs showed no thickened roots or visible tissue damage (Fig. 6c) while 145 DHLs showed those strong phenotypes (Fig. 6d). When both criteria of growth and damage were used to score the population,

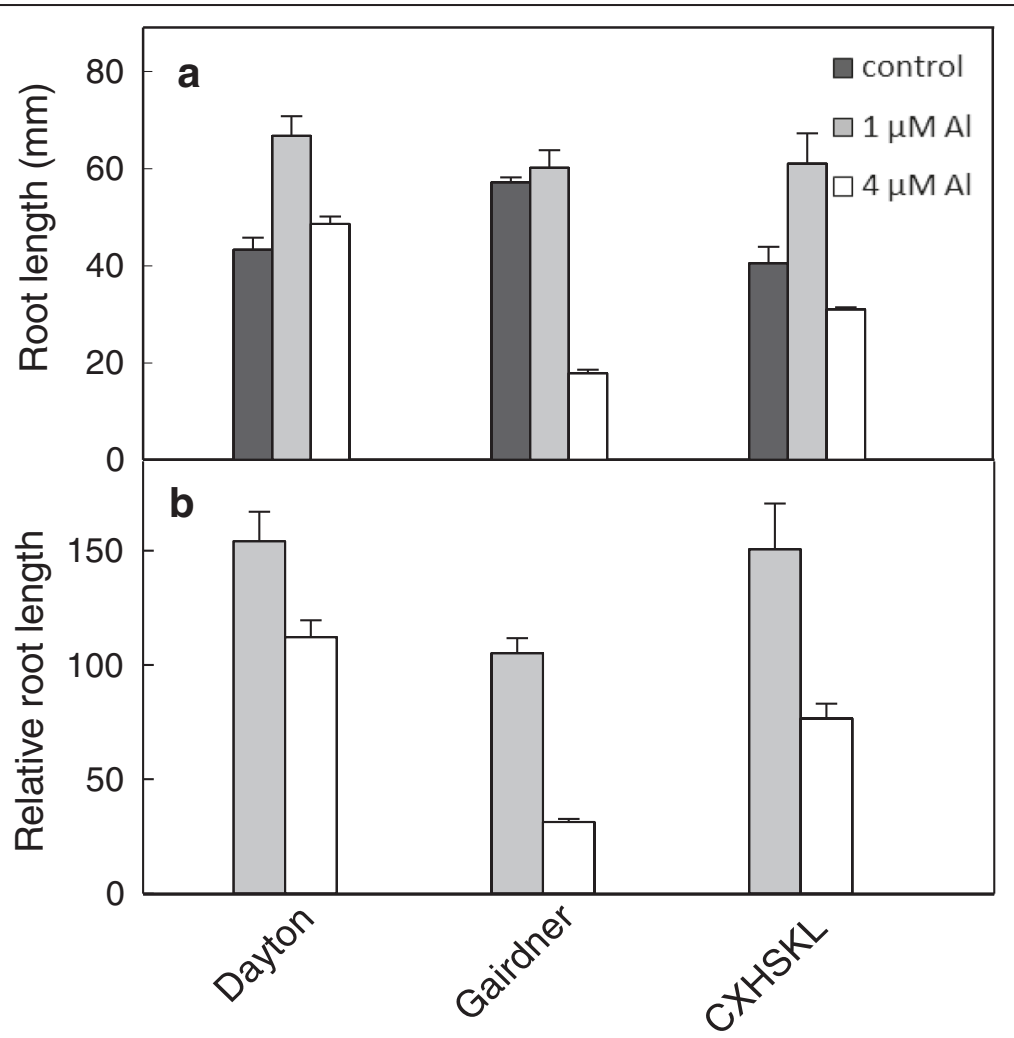

Fig. 2 Comparison of Al tolerance in hydroponic culture. a Net root growth of seedlings after four days in nutrient solution containing 0,1 or $4 \mu \mathrm{M} \mathrm{AlCl}_{3}(\mathrm{pH}=4.3)$. b Relative root length at each Al concentration in contrast with controls. Data showed means and standard error (SE) $(n=4-7)$ 


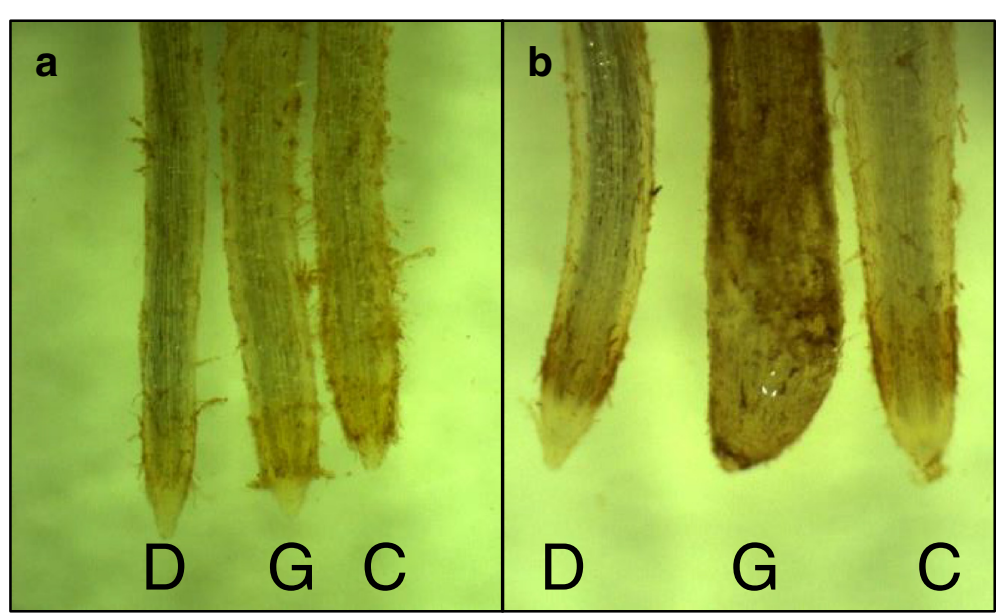

Fig. 3 Comparison of haematoxylin staining of barley roots in hydroponic experiments following different treatments. Shown are root apices after $4 \mathrm{~d}$ in (a) control solution and (b) $4 \mu \mathrm{M} \mathrm{AlCl}_{3}$. Genotypes shown are Dayton (D), Gairdner (G) and CXHKSL (C). Darker staining indicated greater Al accumulation at the root apices

we found that 128 DHLs had root lengths $\leq 50 \mathrm{~mm}$ and showed thickened root apices and 52 DHLs had root lengths $\geq 70 \mathrm{~mm}$ without visible thickening of the root apices (Fig. 5; Fig. 6). The remaining 30 DHLs had root lengths from 55 to $65 \mathrm{~mm}$ of which 17 DHLs showed thickening of the root apices (Fig. 6d).

Preliminary genetic analysis localised the Al tolerance phenotype in CXHKSL to a single major locus on chromosome $4 \mathrm{H}$ (data not shown). Therefore a more detailed genetic linkage map on chromosome $4 \mathrm{H}$ was generated using three SSR markers linked to $\mathrm{Al}$ tolerance (HVM03, Bmag353, Bmac310) as well as the HvMATE21 marker which targets an 21-bp deletion in tolerant genotypes in the 3'UTR of HvAACT1. The map spanned a total length of $17.8 \mathrm{cM}$ and the order of markers (Fig. 7) was similar to Bian et al. [18]. Analysis of root length under $\mathrm{Al}$ toxicity using this linkage map identified a significant QTL with a LOD score of 56.44 (Fig. 8). The closest marker, HvMATE-21, accounted for $71.0 \%$ of the phenotypic variation, while Bmag353 and Bmac310 explained $61.0 \%$ and $50.5 \%$ of the variation respectively (Fig. 8 ). We conclude that $\mathrm{Al}$ tolerance in CXHKSL maps to the HvAACT1 gene as reported for other tolerant barley lines. This was further tested with the HvAACT1 5' UTR marker on a selection of tolerant and sensitive DHLs. All sensitive DHLs tested amplified a band similar to the Gairdner parent which is consistent with expectations. Similarly, all tolerant DHLs tested failed to produce a band which is the same as the CXHKSL parent (data not shown).

Citrate efflux was also measured from the selection of tolerant and sensitive DHLs. Six tolerant DHLs were

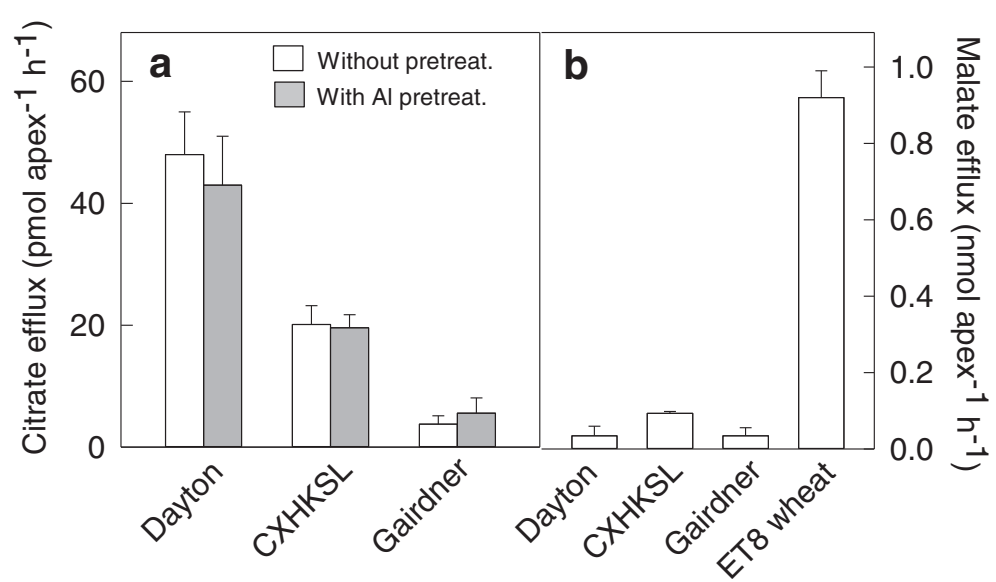

Fig. 4 Citrate and malate efflux from the root apices of the barley varieties. a Citrate efflux was measured in presence of $30 \mu \mathrm{M} \mathrm{AlCl} 3$ with and without an overnight pre-treatment in $10 \mu \mathrm{M} \mathrm{AlCl}_{3}$. b Malate efflux measured in the presence of $30 \mu \mathrm{M} \mathrm{AlCl}{ }_{3}$ without pre-treatment. ET8 is an Altolerant wheat line used as a positive control for malate efflux. Data show means and SE $(n=4)$ 


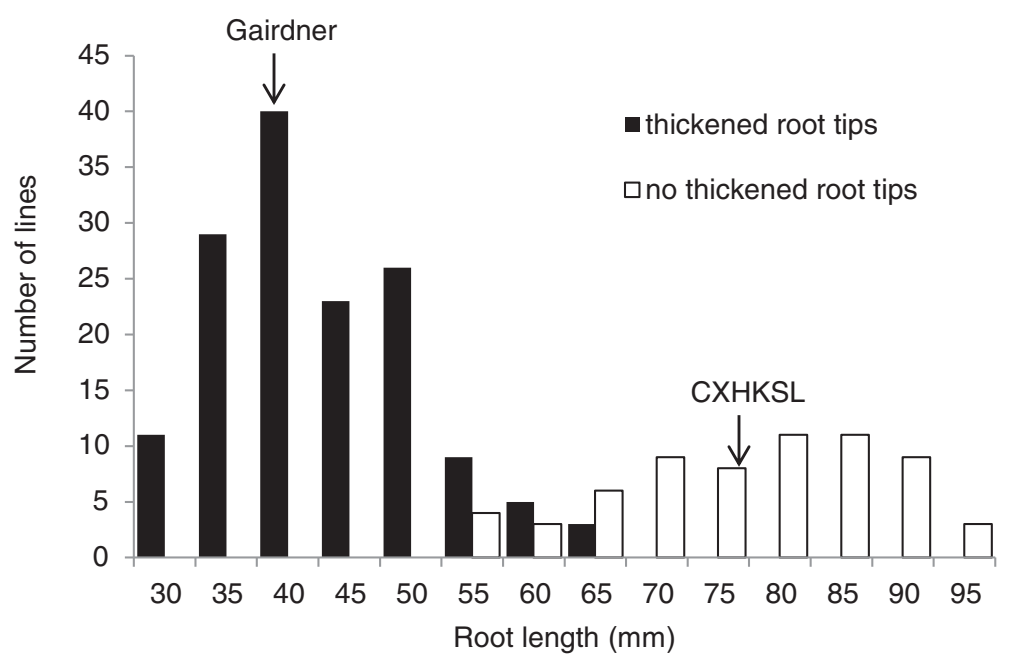

Fig. 5 Distribution frequency of root length of $210 \mathrm{DHLs}$ including parents after growth in an acid soil $(\mathrm{pH}=4.3)$. Solid bars indicated genotypes with thickened root tips and white bars indicate genotypes without thickened root tips

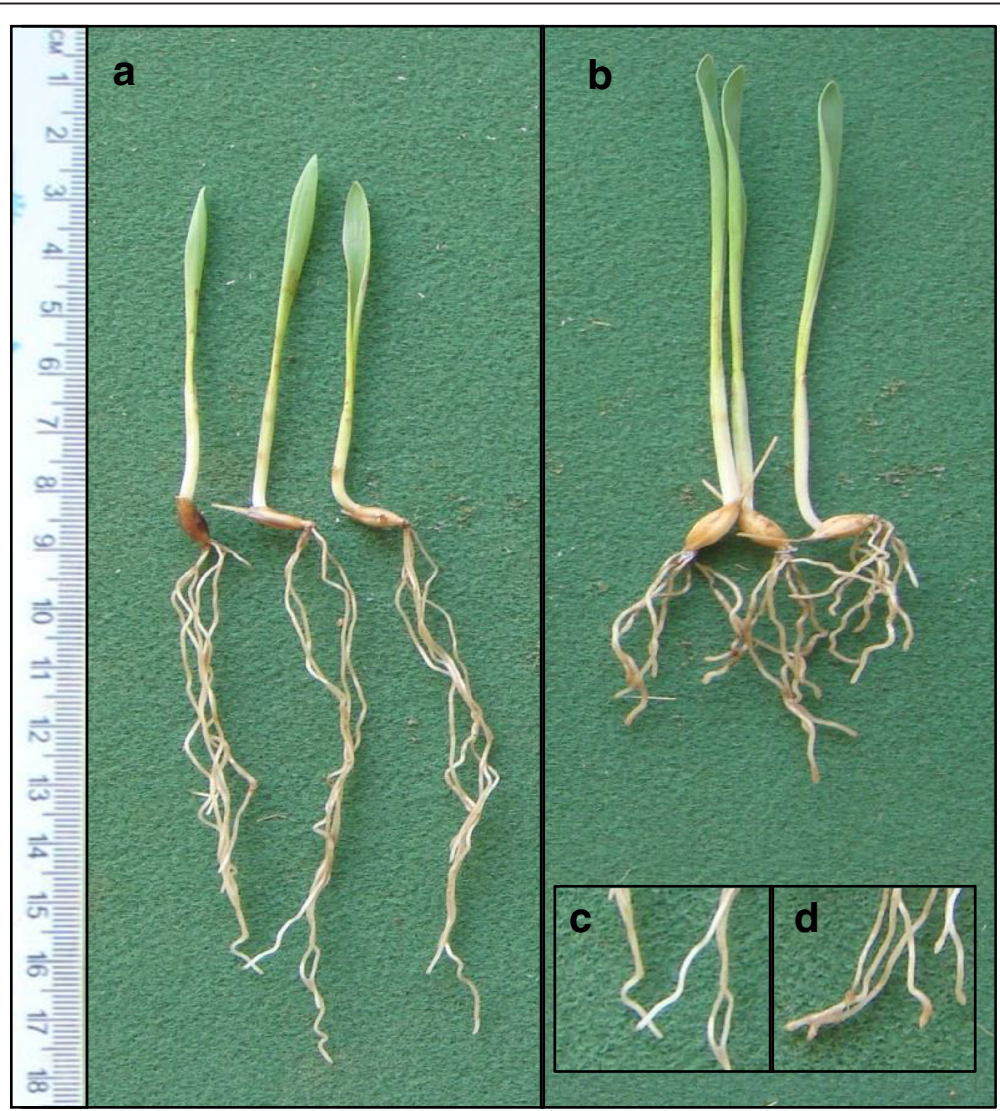

Fig. 6 Comparison of Al tolerance of two parental varieties grown in acid soil $(\mathrm{pH}=4.3)$ by root length and damages to root tips. Root length was compared between (a) CXHKSL and (b) Gairdner. Typical root apices from an Al-tolerant genotype is shown in (c) and typical root apices from a sensitive genotype with obvious thickening and damage is show in (d) 


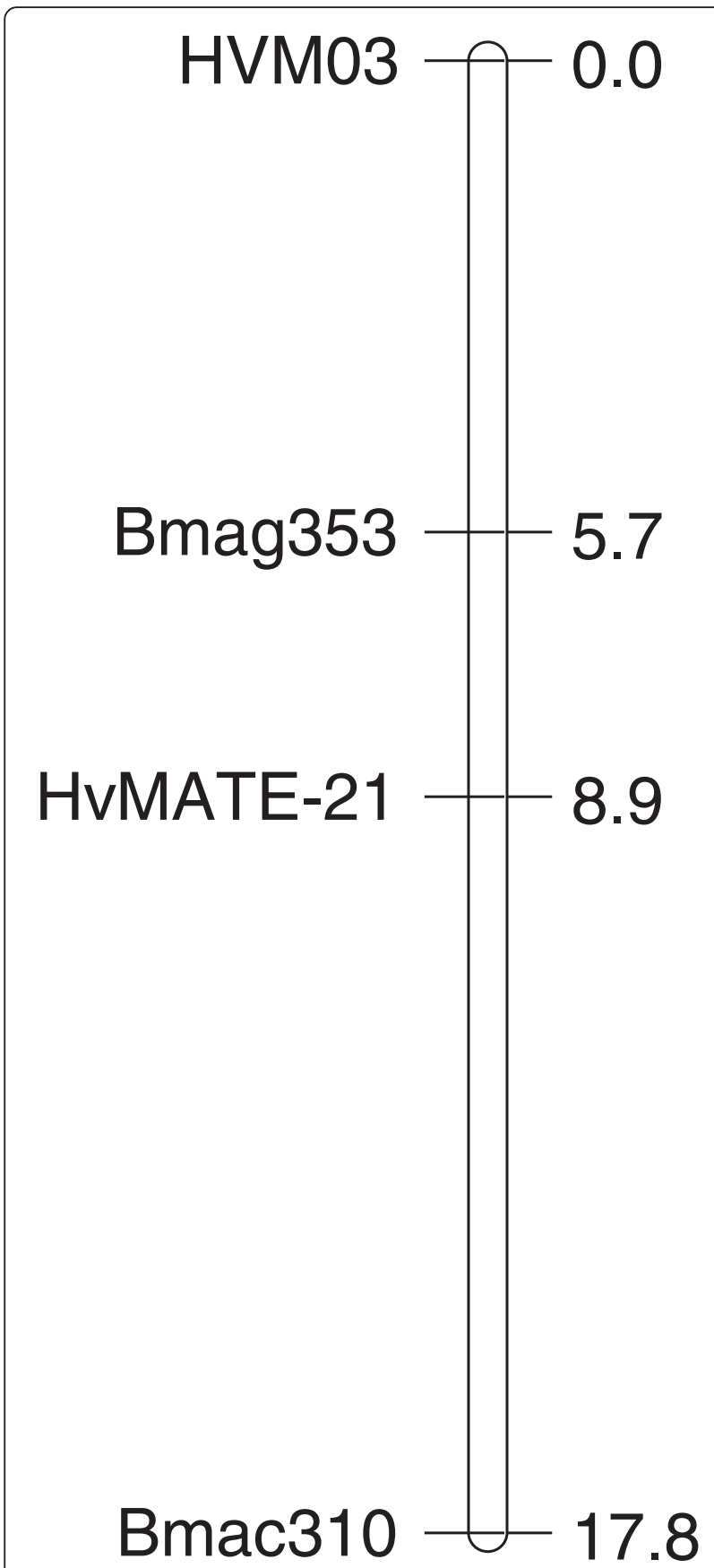

Fig. 7 The linkage map on chromosome $4 \mathrm{H}$ with four molecular markers used to score $210 \mathrm{DHLS}$. Numbers on the right side represented genetic distances in unit of centiMorgan (cM)

examined and efflux was measured from all of them. Five of these had efflux of 18 to $28 \mathrm{pmol} \cdot \mathrm{apex}^{-1} \cdot \mathrm{h}^{-1}$ which was similar to the CXHKSL parent (Fig. 9). Efflux from the remaining tolerant line was lower than the other five but greater than the sensitive lines measured which were $<5 \mathrm{pmol} \cdot$ apex $^{-1} \cdot \mathrm{h}^{-1}$ (Fig. 9). The level of HvAACT1 expression was also determined in selected

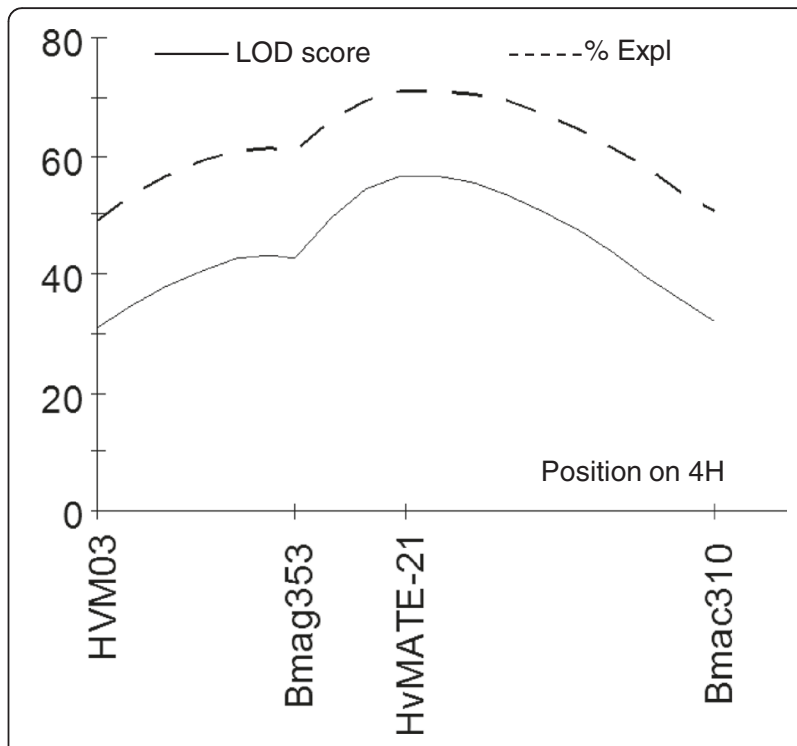

Fig. 8 QTL detected for Al tolerance on chromosome $4 \mathrm{H}$ using root length variation in acid soil. The continuous line represented for the LOD score and the dashed line for phenotype variation (\%) explained by each marker

DHLs to determine whether this was linked with the other phenotypes of tolerance and citrate efflux. These measurements used two different reference genes $H v G A P D H$ and HveEF-1A. Expression of HvAACT1 was detected in CXHKSL, Dayton and the tolerant DHLs tested but no expression was detected in Gairdner or the three sensitive DHLs tested (Fig. 10). These results suggest that Al-tolerance in CXHKSL is controlled by a novel allele of the $H v A A C T 1$ gene.

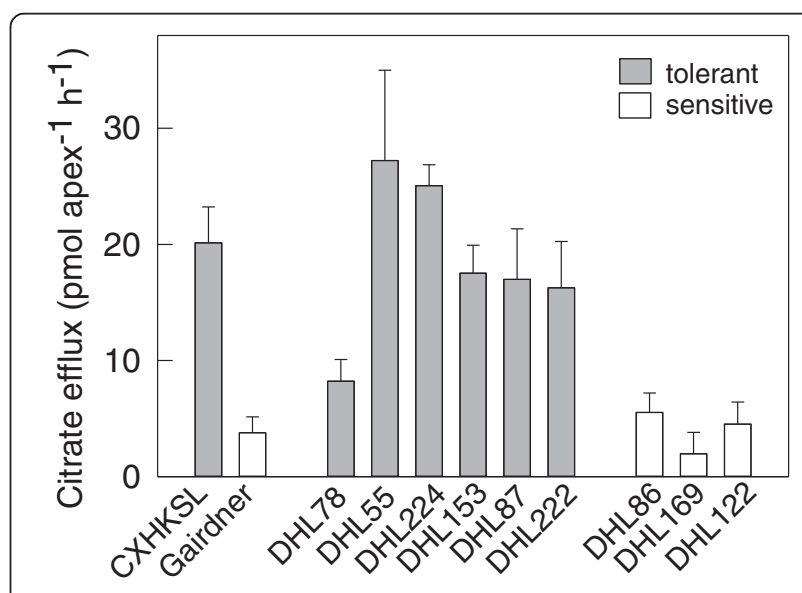

Fig. 9 Citrate efflux from the root apices of the barley lines. Citrate efflux from CXHKSL and Gairdner as well as Al tolerant and sensitive DHLs in the presence of $30 \mu \mathrm{M} \mathrm{AlCl}$ w without Al pre-treatment. Data showed means and SE $(n=4)$ 


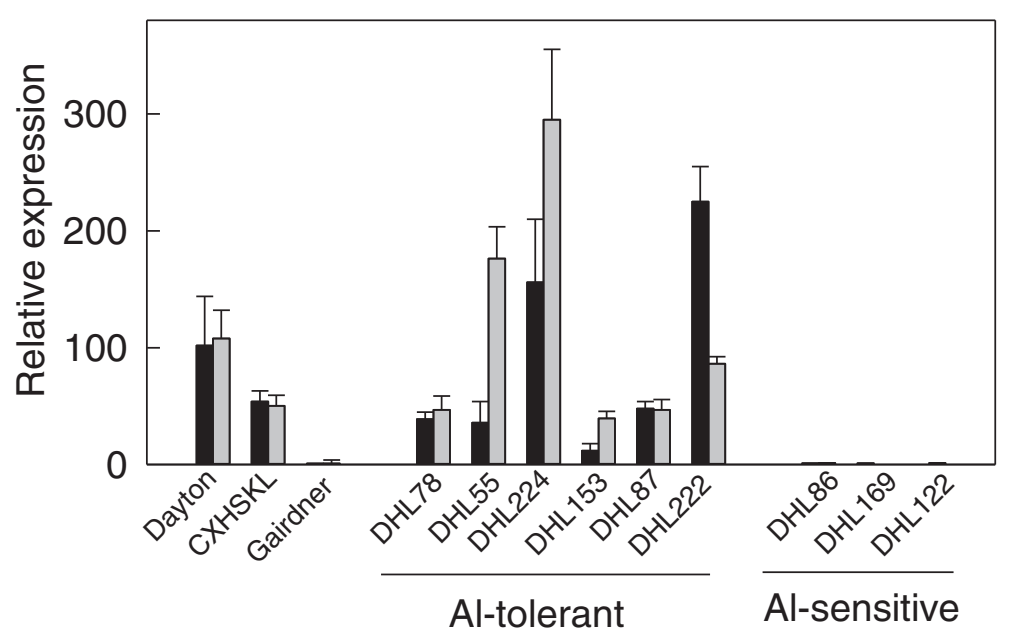

Fig. 10 Relative expression of HVAACT1 in Al-sensitive and Al-tolerant DH lines generated from Gairdner and CXHSKL measured with quantitative RT-PCR. The Al-tolerant variety Dayton was included. Expression of Gairdner was designated as 1.0. Data showed means of relative expression level using HVGAPDH (black bars) and HveEF-1A (shaded bars) as reference genes, and SE from three biological replicates with two

technical replicates

\section{Discussion}

The only mechanism of Al tolerance in barley described to date relies on the release of citrate from the root apices via the HvAACT1 transporter [14-16]. In our study, we characterised a Chinese barley variety CXHKSL which is moderately tolerant to $\mathrm{Al}$ stress in hydroponics and acid soil but did not generate the expected result for a standard marker that targets the $1 \mathrm{~kb}$ insert in the 5'UTR of HvAACT1 correlated with Al tolerance. Dayton and Gairdner amplified fragments of expected sizes from the 5'UTR of $H v A A C T 1$ while no PCR products were detected in CXHKSL. The determinant role of promoter variation in $\mathrm{Al}$ tolerance was further confirmed by the fact that only one SNP was detected for CDS of HvAACT1 gene between CXHKSL and Dayton without causing changes in protein sequence. We showed that the $\mathrm{Al}$ tolerance mechanism in CXHKSL likely relies on the Al-activated efflux of citrate reported for other tolerant barley. Using a DH population generated by crossing CXHKSL and the Al-sensitive variety Gairdner and a set of markers linked with $\mathrm{Al}$ tolerance, we found that the tolerance locus in CXHKSL mapped to HvAACT1. Collectively these results suggest that CXHKSL possesses a novel allele of Al-tolerance gene HVAACT1.

Fuji et al. [23] reported that $\sim 1 \mathrm{~kb}$ insertion in the upstream 5'UTR of $H v A A C T 1$ alters the distribution and level of gene expression in Al-tolerant cultivars. We tried to detect the presence of this insert using the published pair of primers but no fragments were amplified in CXHKSL or the tolerant DH lines tested. However, the expression level of HvAACT1 in CXHKSL, Dayton and Gairdner was positively correlated with the relative $\mathrm{Al}$ tolerance of these varieties with Dayton $>$ CXHKSL >
Gairdner. We also found that $H v A A C T 1$ expression was higher in the tolerant DHLs than sensitive DHLs and that the marker targeting the 5' UTR of HvAACT1 segregated with tolerance (absence of a band in CXHKSL). This is consistent with the central role of HvAACT1 in Al tolerance in these barley lines [23]. The absence of a PCR product with the 5'UTR HvAACT1 marker in CXHKSL could be due to polymorphisms which prevented primer binding to the DNA. We tested this possibility by designing the additional primers from the same region but these also failed to generate a product in CXHKSL (Fig. 1c). The absence of a PCR product for this marker could also be due to a deletion in CXHKSL or the presence of a much larger insert. It is clear that polymorphisms exist in the 5'UTR of HvAACT1 in CXHKSL compared to the published sequences for other tolerant barley [23].

The gene-specific marker HvMATE-21 was more efficient in predicting the phenotypic variation $(71.0 \%$ in this study, Fig. 8) under Al toxicity than other commonly-used SSR markers, Bmac310 and Bamag353 $[16,19,20]$. Meanwhile, segregation distortion occurred in the $\mathrm{DH}$ population which skewed the distribution of root lengths toward the sensitive parent Gairdner and away from Mendelian expectations. No significant monogenic segregation ratio $1: 1\left(\chi^{2}=36.82>\chi^{2} \quad 0.05=\right.$ 3.84) was observed. This distortion can occur when the generation of fertile hybrids are prevented as a result of the methods used to produce the lines $[18,30]$.

$\mathrm{Al}$ tolerance of wheat primarily relies on the $\mathrm{Al}$ dependent malate efflux from root apices which is controlled by the Al-activated anion transporter encoded by the TaALMT1 gene [31]. The closest homologue of this 
gene in barley is HvALMT1 which is located on chromosome $2 \mathrm{H}$ and does not contribute to the $\mathrm{Al}$ resistance [32]. However, over-expression of HvALMT1 gene in barley with a constitutive promoter can increase the efflux of malate and $\mathrm{Al}$ tolerance in barley and wheat [33]. The contribution of malate efflux to Al tolerance was investigated in CXHKSL and other tolerant and sensitive genotypes but no significant malate release was detected.

\section{Conclusions}

In the present study, we demonstrated that CXHKSL possesses a novel allele for the major $\mathrm{Al}$ tolerance gene HvAACT1 but the mechanism of tolerance is similar to other tolerant barley lines.

\section{Availability of supporting data}

The data sets supporting the results of this article are included within the article.

\section{Additional files}

Additional file 1: Table S1. Acid soil tolerance of barley accessions:

The acid soil with pH 4.3 was collected from Northern Tasmania. Acid soil was placed in a tray (length of $2 \mathrm{~m}$, width of $1 \mathrm{~m}$ and depth of $0.4 \mathrm{~m}$ ) in a temperature-controlled glasshouse under a $16 \mathrm{~h} / 8 \mathrm{~h}$ light/dark cycle (22 and $18{ }^{\circ} \mathrm{C}$, respectively). Water level was controlled using an automatic watering system (XLSX $15 \mathrm{~kb}$ )

Additional file 2: Table S2. List of primers used for isolations and sequencing coding regions of the HVAACT1 gene (DOCX $14 \mathrm{~kb}$ )

Additional file 3: Figure S1. HVAACT1 coding region in CXHKSL and Dayton. SNPs are shown in white background. (DOCX 149 kb)

\section{Abbreviations}

CDS: coding DNA sequence; DH: double haploid; DHLs: double haploid lines; IM: interval mapping; INDEL: insertion-deletion; MATE: multidrug and toxic compound extrusion; MQM: multiple QTL mapping; ORF: open reading frame; QTL: quantitative trait loci; RRL: relative root length; RT-

PCR: quantification real time polymerase chain reaction; SSR: simple sequence repeats; UTR: untranslated region.

\section{Competing interests}

The authors declare that they have no competing interests.

\section{Authors' contributions}

YM conducted the bulk of experiments and wrote the paper draft. MZ was responsible for experimental design, data interpretation and writing. JY and $J$ conducted the experiments. CDL, PR, SS and CJL contributed to data interpretation and writing. All authors have read and approved the manuscript.

\section{Acknowledgements}

This work is supported by the Grains Research and Development Corporation of Australia.

\section{Author details}

'Tasmanian Institute of Agriculture and School of Land and Food, University of Tasmania, P.O. Box 46, Kings Meadows, TAS 7249, Australia. ${ }^{2}$ Western Barley Genetics Alliance, Murdoch University, 90 South Street, Murdoch, WA 6150, Australia. ${ }^{3}$ CSIRO Agriculture, GPO Box 1600, Canberra, ACT 2601, Australia. ${ }^{4}$ CSIRO Agriculture, 306 Carmody Road, St Lucia, QLD 4067, Australia.
Received: 16 May 2015 Accepted: 28 February 2016

Published online: 05 March 2016

\section{References}

1. Kochian LV. Cellular mechanisms of aluminum toxicity and resistance in plants. Annu Rev Plant Physiol Plant Mol Biol. 1995;46:237-60.

2. Melakeberhan $\mathrm{H}$, Bird GW, Jones AL. Soil pH affects nutrient balance in cherry rootstock leaves. HortScience. 2001;36:916-7.

3. Parker DR. Root growth analysis: an under-utilised approach to understanding aluminium rhizotoxicity. Plant Soil. 1995;171:151-7.

4. Ryan PR, Shaff JE, Kochian LV. Aluminium toxicity in roots: correlation between ionic currents, ion fluxes and root elongation in Al-tolerant and Alsensitive wheat varieties. Plant Physiol. 1992;99:1193-200.

5. Amenos M, Corrales I, Poschenrieder C, Illes P, Baluska F, Barcelo J. Different effects of aluminum on the actin cytoskeleton and brefeldin A-sensitive vesicle recycling in root apex cells of two maize varieties differing in root elongation rate and aluminum tolerance. Plant Cell Physiol. 2009;50:528-40.

6. Foy CD. Physiological effects of hydrogen, aluminium, and manganese toxicities in acid soil. In: Pearson RW, Adams F, editors. Soil acidity and liming. Wisconsin: Amer Soc. Agronomy; 1984. p. 57-97.

7. Ryan PR, DiTomaso JM, Kochian LV. Aluminium toxicity in roots: an investigation of spatial sensitivity and the role of the root cap. J of Exp Bot. 1993:44:437-46

8. Zhou G, Delhaize E, Zhou M, Ryan PR. The barley MATE gene, HVAACT1, increases citrate efflux and $\mathrm{Al}^{3+}$ tolerance when expressed in wheat and barley. Ann Bot. 2013;112:603-12.

9. Ciamporova M. Morphological and structural responses of plant roots to aluminium at organ, tissue, and cellular levels. Biol Plantarum. 2002; 45:161-71.

10. Zelinova V, Haluskova L, Huttova J, Illes P, Mistrik I, Valentovicova K, et al. Short-term aluminium-induced changes in barley root tips. Protoplasma. 2011;248:523-30.

11. Delhaize E, Ma J, Ryan PR. Transcriptional regulation of aluminium tolerance genes. Trends Plant Sci. 2012;17:341-8.

12. Maron LG, Guimaraes CT, Kirst M, Albert PS, Birchler JA, Bradbury PJ, et al. Aluminum tolerance in maize is associated with higher MATE1 gene copy number. Proc Natl Acad Sci U S A. 2013;110:5241-6.

13. Ryan PR, Tyerman SD, Sasaki T, Yamamoto Y, Zhang WH, Delhaize E. Identification of aluminium-resistance genes in plants provides an opportunity for enhancing the acid-soil tolerance of crop species. J Exp Bot. 2011;62:9-20.

14. Ma J, Nagao S, Sato K, Ito H, Furukawa J, Takeda K. Molecular mapping of a gene responsible for Al-activated secretion of citrate in barley. J Exp Bot. 2004:55:1335-41.

15. Furukawa J, Yamaji N, Wang H, Mitani N, Murata Y, Sato K, et al. An aluminum-activated citrate transporter in barley. Plant Cell Physiol. 2007;48: 1081-91.

16. Wang J, Raman H, Zhou M, Ryan PR, Delhaize E, Hebb DM, et al. Highresolution mapping of the Alp locus and identification of a candidate gene HVMATE controlling aluminium tolerance in barley (Hordeum vulgare L.). Theor Appl Genet. 2007;115:265-76.

17. Ma J, Ryan PR, Delhaize E. Aluminium tolerance in plants and the complexing role of organic acids. Trends Plant Sci. 2001;6:273-8.

18. Ryan PR, Delhaize E, Jones DL. Function and mechanism of organic anion exudation from plant roots. Annu Rev Plant Physiol Plant Mol Biol. 2001;52: 527-60

19. Bian M, Waters I, Broughton S, Zhang X, Zhou M, Lance R, et al. Development of gene-specific markers for acid soil/aluminium tolerance in barley (Hordeum vulgare L.). Mol Breed. 2013:32:155-64.

20. Raman H, Moroni JS, Sato K, Read BJ, Scott BJ. Identification of AFLP and microsatellite markers linked with an aluminium tolerance gene in barley (Hordeum vulgare L.). Theor Appl Genet. 2002;105:458-64.

21. Tang $Y$, Sorrells ME, Kochian LV, Garvin DF. Identification of RFLP markers linked to the barley aluminum tolerance gene Alp. Crop Sci. 2000:40:778-82

22. Wang J, Harsh R, Zhang G, Mendham N, Zhou M. Aluminium tolerance in barley (Hordeum vulgare L.): physiological mechanisms, genetics and screening methods. J Zhejiang Univ Sci B. 2006;7:769-87.

23. Fujii M, Yokosho K, Yamaji N, Saisho D, Yamane M, Takahashi H, et al. Acquisition of aluminium tolerance by modification of a single gene in barley. Nat Commun. 2012;3:713 
24. Raman H, Karakousis A, Moroni JS, Raman R, Read BJ, Garvin DF, et al. Development and allele diversity of microsatellite markers linked to the aluminium tolerance gene Alp in barley. Aust J Agric Res. 2003;54:1315-21.

25. Delhaize E, Ryan PR, Hebb DM, Yamamoto Y, Sasaki T, Matsumoto $H$. Engineering high-level aluminum tolerance in barley with the ALMT1 gene. Proc Natl Acad Sci U S A. 2004;101:15249-54.

26. Ryan PR, Delhaize E, Randall PJ. Characterisation of Al-stimulated efflux of malate from the apices of Al-tolerant wheat roots. Planta. 1995;196:103-10.

27. Liang HW, Wang CZ, Li Z, Luo XZ, Zou GW. Improvement of the silverstained technique of polyacrylamide gel electrophoresis (in Chinese). Hereditas (Beijing). 2008;30:1379-82.

28. Van Ooijen JW. JoinMap 4.0, Software for the calculation of genetic linkage maps. Wageningen: Plant Research International; 2006.

29. Van Ooijen JW. MapQTL 6, Software for the mapping of quantitative trait loci in experimental populations of diploid species. Wageningen, The Netherlands: Kyazma BV; 2009.

30. Zhu CS, Wang CM, Zhang YM. Modeling segregation distortion for viability selection I. Reconstruction of linkagemaps with distorted markers. Theor Appl Genet. 2007;114(2):295-305.

31. Sasaki T, Ryan PR, Delhaize E, Hebb DM, Ogihara Y, Kawaura K, et al. Sequence upstream of the wheat (Triticum aestivum L.) ALMT1 gene and its relationship to aluminum resistance. Plant Cell Physiol. 2006;47:1343-54.

32. Gruber BD, Ryan PR, Richardson AE, Tyerman SD, Sunita R, Hebb DM, et al. HVALMT1 from barley is involved in the transport of organic anions. J Exp Bot. 2010;61:1455-67.

33. Gruber BD, Delhaize E, Richardson AE, Roessner U, James RA, Howitt SM, et al. Characterisation of HVALMT1 function in transgenic barley plants. Funct Plant Biol. 2011;38:163-75.

\section{Submit your next manuscript to BioMed Central and we will help you at every step:}

- We accept pre-submission inquiries

- Our selector tool helps you to find the most relevant journal

- We provide round the clock customer support

- Convenient online submission

- Thorough peer review

- Inclusion in PubMed and all major indexing services

- Maximum visibility for your research

Submit your manuscript at www.biomedcentral.com/submit 